Article

\title{
Towards Supporting Collaborative Spatial Planning: Conceptualization of a Maptable Tool through User Stories
}

\author{
Rosa Aguilar*(D), Johannes Flacke $\mathbb{D}$ and Karin Pfeffer $\mathbb{D}$ \\ Faculty of Geo-Information Science and Earth Observation, University of Twente, P.O. Box 217, \\ 7500 AE Enschede, The Netherlands; j.flacke@utwente.nl (J.F.); k.pfeffer@utwente.nl (K.P.) \\ * Correspondence: r.m.aguilardearchila@utwente.nl; Tel.: +31-647-616-029
}

Received: 10 December 2019; Accepted: 30 December 2019; Published: 3 January 2020

check for updates

\begin{abstract}
Geographic information-based planning support tools implemented in a maptable have the potential to mediate collaborative spatial planning processes. However, available tools for a maptable either lack advanced analytical functions or have usability shortcomings. Given these limitations, this research aims to conceptualize an interactive planning support tool intended to fully exploit maptable capabilities while providing spatial analytical functions to better support planning and decision-making processes with a larger group of participants. To do so, we conducted a literature review of reported maptable-based applications and semi-structured interviews with identified intended user groups of such applications, and derived Agile user stories. We identified a) principal spatial analyses, b) must-have functionalities, c) required support for individual contributions, and d) preferred space-time settings for group work collaboration, and based on that conceptualized an interactive tool for a maptable. By involving the intended users in the conception of the tool we revealed a discrepancy between the understanding of scholars and developers with respect to what users need and what they do. Intended user groups require tailored but straightforward instruments, rather than complicated or time-consuming models. Our research has laid down the foundation for future maptable tool development to support collaborative planning processes.
\end{abstract}

Keywords: collaborative planning; maptable; interactive; support

\section{Introduction}

Geographic information (GI) based planning support tools which offer interactive map visualization and analytical capabilities have the potential to mediate collaborative spatial planning processes. The shift from rational planning to communicative planning has promoted the utilization of such (digital) geo-tools as mediators for social interaction in addressing spatial planning problems [1-4]. However, planning practitioners have not fully incorporated Planning Support Systems (PSS) in their practice despite the variety of such tools developed to aid spatial planning tasks $[5,6]$. This problem, known as "the implementation gap" [3,7-9], is explained by certain characteristics of PSS such as low usability, vast requirements of expert knowledge or user unawareness of the PSS potentials $[4,10]$.

A maptable is a PSS tool to support collaborative spatial planning processes usually arranged in a PSS workshop $[3,11,12]$. The primary characteristic of a maptable is the utilization of a large horizontal touch table that allows interacting with geospatial content. A maptable facilitates the communication process by providing a GI-based visual platform easy to understand by the majority of users regardless of their IT literacy or knowledge background [13]. Besides, the physical characteristics of the platform, its size, and horizontal orientation enable more equitable participation as all members are located around the content being able to contribute to the discussion [14]. The enhanced interaction provided 
by a maptable might lead towards social learning, knowledge sharing, knowledge integration or consensus-building [15-17]. Maptables have been applied in different fields, among others, energy transition [18], proposals for green and blue infrastructure [15] or development of long term adaptation strategy in peatlands [19].

Regardless of the proven and claimed benefits of a maptable, such as an enhanced interaction among different types of stakeholders or an improved negotiation led by the interactive feedback on measures being discussed [20], three principal factors constrain the use of a maptable in a PSS workshop. First, there are limited software applications specifically designed for a maptable [21]. Moreover, typical applications reported in the literature have usability shortcomings that prevent users from achieving a satisfactory user experience because they have single-user roots meaning that those applications were designed for a desktop computer [7]. Second, a maptable can only accommodate a limited number of people in a PSS workshop. A typical maptable can host four to six participants at the maximum. Third, so far, a maptable PSS is only applied in a co-located and synchronous setting for group work collaboration [21]. However, certain collaborative spatial planning processes may require the contribution of participants in a different group work setting, e.g., people remotely located and not able to participate in a specific place at a specific time, or a larger audience that cannot be easily accommodated in a room.

Given the mentioned shortcomings, this research aims to conceptualize an interactive PSS tool for maptables specifically intended to fully exploit maptable capabilities while providing spatial analytical functions to better support planning and decision-making processes with a larger group of participants. To do so, we applied a combination of methods, namely a literature review of reported maptable-based applications, semi-structured interviews with identified intended user groups of those applications and Agile user stories. The interviews with intended users and their user stories served to involve expectations of intended users at the conceptualization—i.e., primary stage—of the development project of our tool.

The paper is structured as follows: Section 2 provides a synopsis of important elements of the tool conceptualization. Section 3 elaborates the methods used to collect and analyze data; Section 4 presents the results including the conceptualization of the tool, whereas Section 5 discusses them, presents conclusions, and outlines future research directions.

\section{Background}

In this section, we elaborate on maptable-based PSS workshops to enlighten the organizational, technical, and physical aspects that should be considered when designing an interactive tool to support such a collaborative activity. Besides, we briefly illustrate the different space-time settings where collaborative planning processes can occur and the digital support they might require. Moreover, we introduce human centered design (HCD) and Agile user stories since we aim to conceptualize a PSS tool to be used in a maptable based on user needs.

\subsection{A Maptable-Based PSS Workshop/Process}

In this research we define, based on the literature and our own expertise, a maptable-based PSS workshop as a structured meeting that provides a physical space and maptable(s) as a primary digital supporting tool(s) to facilitate the interaction among participants during collaborative, participatory processes [18,22,23]. A maptable-based PSS workshop has three fundamental elements, namely (a) the planning problem context, (b) the purpose or intended outcome of the PSS workshop, and (c) the planning phase in which the workshop takes place (see Figure 1). The planning problem context involves the nature of the planning problem, stakeholders, and their setting concerning space and time. The planning problem refers to the issue being discussed, for instance, matters related to the use of land, infrastructure development, or facilities allocation [24]. The nature of the problem comprises its complexity, degree of structuration $[25,26]$, and geographic scope. It defines the stakeholders to be involved-i.e., the individuals, groups, public or private organizations, and institutions that may have 
a stake in the problem [27] - and their characteristics such as knowledge, skills, experience, education, habits or preferences, geographic distribution, and time for participation [28]. The purpose refers to the intended outcome of the workshop [22], meaning what is expected to be achieved from the stakeholder participation, e.g., design of proposals, consensus-building concerning the allocation of resources or learning about a particular problem $[16,18,19,29]$. The planning phase and the purpose delineate the orientation of the PSS workshop toward a communicational or an analytical emphasis and the tasks that participants are expected to complete. Lastly, the planning phase [30] plays a vital role in the purpose for which the application is used. For example, in an exploratory phase, more social interaction and communication to frame the problem than to develop concrete plans may be expected. This communication process could be supported by map-based visualization. In other planning phases, such as the design or choice phase, specific discussions which require not only map-based visualization but also analytical support such as impact analysis may be needed [31].

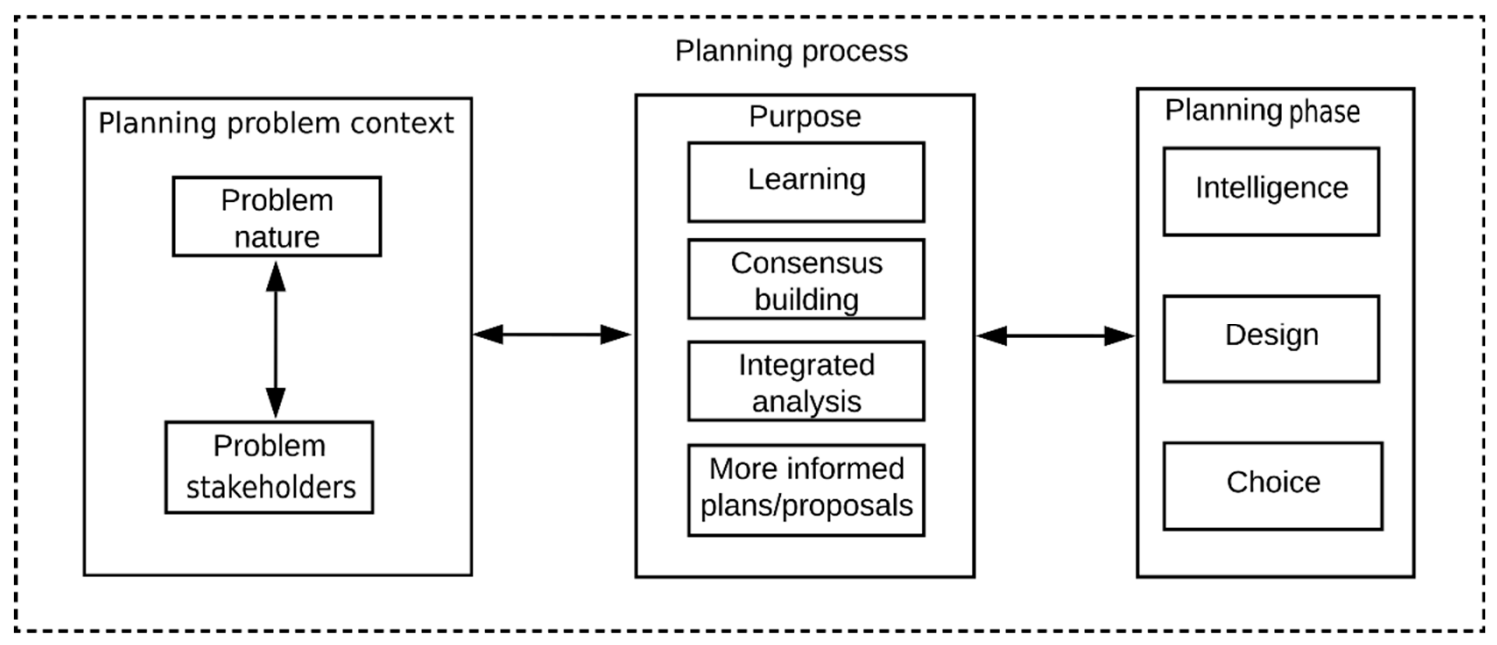

Figure 1. Maptable-based planning workshop context. Source: Authors; based on [3,22,30].

\subsection{Space-Time Dimensionality for Group Work Collaboration}

As mentioned in the introduction, a PSS workshop normally happens in a co-located and synchronous setting for group work collaboration. However, interaction among participants in collaborative planning processes may occur in different space and time settings. Four cases were identified [28,32], namely: a) co-located synchronous: same place and same time, b) distributed synchronous: different place and same time, c) co-located and asynchronous: same place and different time and, d) distributed and asynchronous: different place and different time. Figure 2 illustrates those settings. Various methods for participation are applicable in each setting. For example, a group decision room (GDR), i.e., an electronic mediated meeting room enabling stakeholders dialogue [3] could be a suitable method for co-located and synchronous (same time) discussion. A web survey can be applied to distributed and asynchronous consultation, as has been implemented in SoftGIS [33]. As each setting will require different methods, specific support concerning enabling technologies is required [34].

A maptable is a PSS tool used so far in collaborative processes happening in a co-located and synchronous setting, e.g., a PSS workshop. In this study, inspired by our experiences in observing/ conducting maptable workshops $[17,18,35]$ where participation was limited by the size of maptable(s) applied, we also explore the possibilities to extend maptable capabilities to support a different space-time setting for group work collaboration and how relevant this kind of support for our intended user groups is. 
Space - time settings

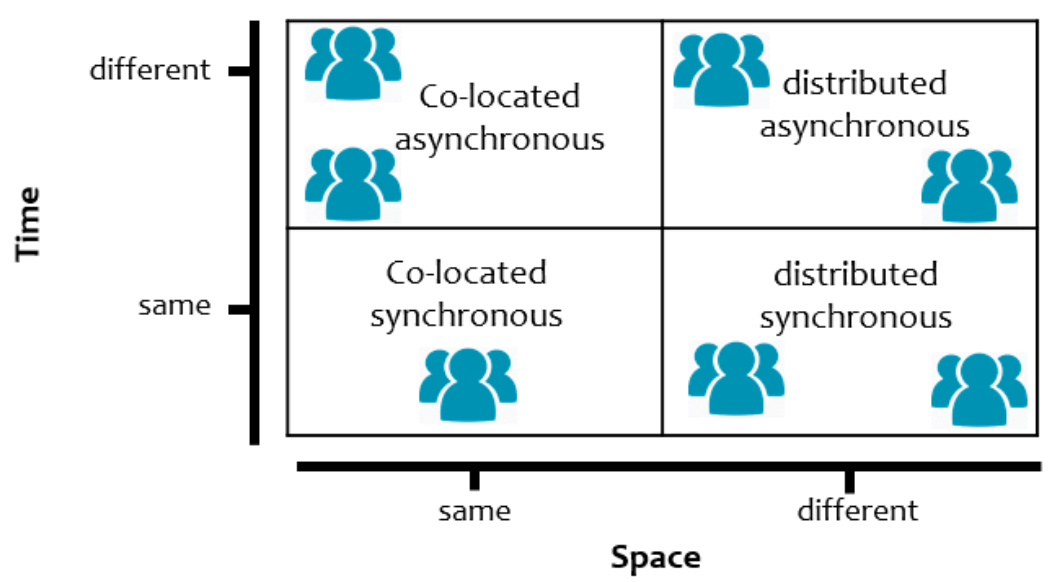

Figure 2. Space-time setting for group work collaboration. Based on [28].

\subsection{Human Centered Design and Agile User Stories}

In the last decades, two main approaches have driven software development, namely humancentered design (HCD), and Agile software development [36]. The HCD approach is an iterative workflow of design and usability evaluation of interactive systems where the (human) user plays a central role. In such a way, the developed system becomes more usable. Agile software development comprises a set of practices to produce software in a short and usually well-defined period complying with user requirements. Agile methods apply incremental and iterative development cycles where the intended users provide feedback, and the goals of the system under development are adapted as user requirements are enlightened [37]. Although HCD and Agile techniques pursue slightly different goals, e.g., Agile techniques focus on working functionalities whereas HCD focuses on the usability, both methods work in close cooperation with the intended users and stakeholders of the system under design/development. The combination of HCD and Agile pursue delivering highly usable software [37] in a short time.

For instance, a user story is a conventional Agile technique for collecting user requirements that encapsulates functional requirements in an informal language as perceived by the user [37] and can be used within a HCD. It usually follows a template of who, what and why [38] as shown in Box 1, although other variants exist. The '[who]' is represented by Persona, i.e., an identified user or user role, the '[what]' describes the capability or software functionality that should be performed and the (optional) '[why]' that is located after the phrase so that, provides the rationality or benefits obtained by having that capability. A user story is an instrument for the dialogue between developers and users, and is often further discussed, for example, to add details and validation criteria, before its implementation. User stories can be gathered through different methods, such as user interviews, questionnaires, observation, and story-writing workshops [39].

Box 1. Standard templates for a user story.

[Persona] wants to [perform a task] so that [achieve this goal] As [user role], I want to [perform a task] so that [achieve this goal]

\section{Methods}

To conceptualize an interactive PSS tool for a maptable we conducted a comprehensive literature review on existing maptable applications to identify 1) potential user requirements of maptable users, and 2) shortcomings of current PSS software for horizontal, large touch devices. Furthermore, we conducted a series of semi-structured interviews with a carefully identified groups of maptable users 
to elicit their needs or expectations regarding the application under study. From these interviews, we derived user stories as concrete expressions of user needs. Moreover, we drew on insights gained from previous maptable-based PSS workshops [18,21]. Those user stories and experiences combined with the required baseline functionality of an online annotated map [40,41] formed the starting point for the conceptualization of the tool that is presented in this article. Figure 3 shows the workflow of our study that is elaborated in the following subsections.

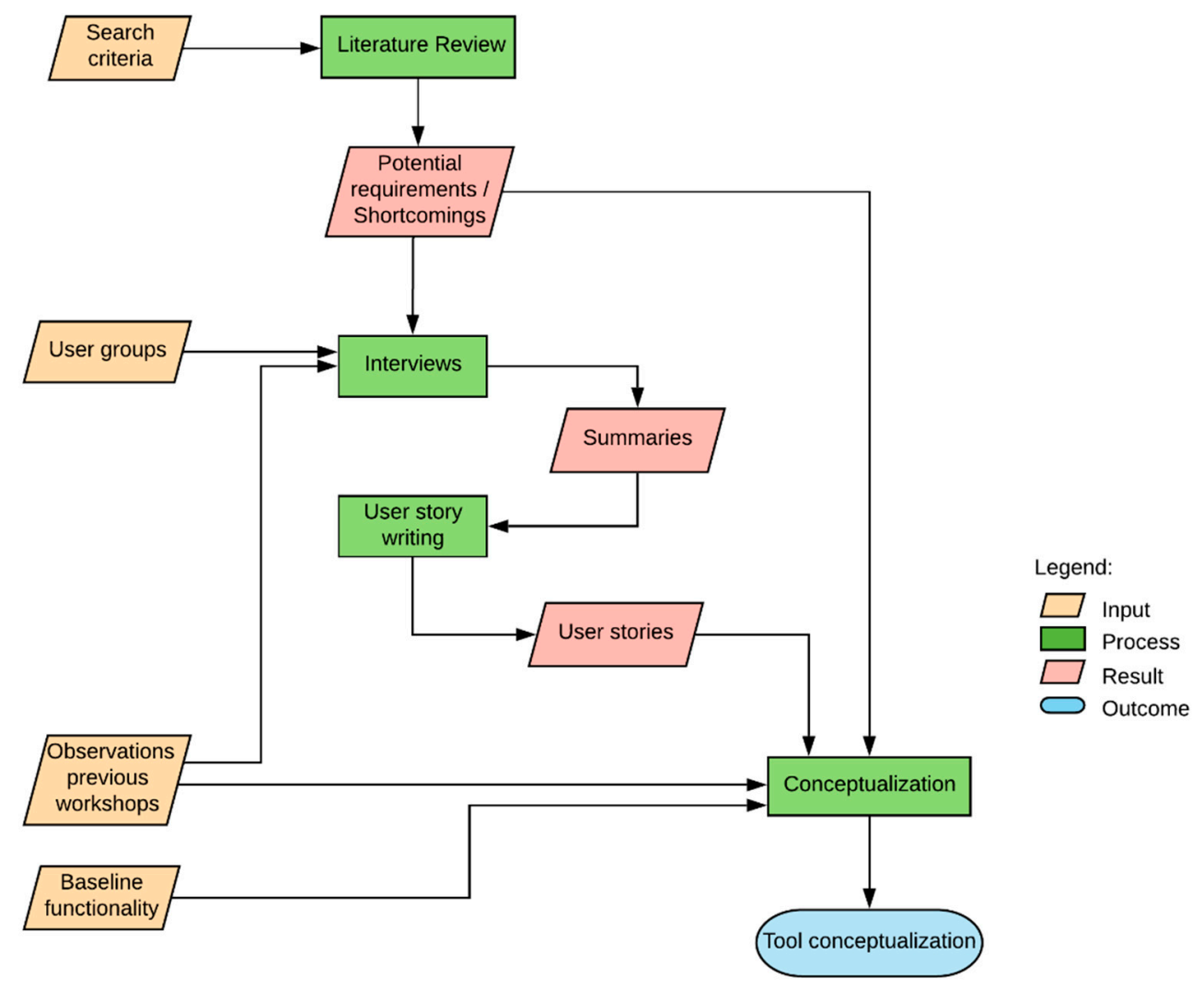

Figure 3. Methodology overview.

\subsection{Literature Review}

Three central sources of literature were reviewed for the period between 2008 and 2018, namely, Google Scholar, Scopus, and Web of Science. In Scopus and Web of Science, each search query was applied to the title, abstract, and article keywords. The criteria and search keywords used to build queries for each database format are given below:

- Keywords: urban planning, tools, maptable, multi-touch, collaboration. Synonyms for maptable: tabletop and touch device. Strings used were:

a) planning AND tools AND maptable AND multi-touch AND collaboration;

b) planning AND tools AND maptable AND collaboration.

- Language: English.

- Type of publication: full text available in journals, proceedings.

Using the term "touch device" in google scholar returned more than 2000 hits. For that reason, that keyword was omitted in that search engine. The total number of papers returned by each source was: a) Google Scholar: 135, b) Scopus: 26, and c) Web of Science: 18. Through manual screening, we omitted non-relevant papers, i.e., papers not directly related to planning, or articles referring to 
tangible user interface (TUI) where the interaction is based on the combination of physical objects and computer vision technologies.

After manual screening the search resulted in 12 papers selected from a) Google Scholar: 10, b) Scopus: 2, and c) Web of Science: 0 (papers were already returned in the other sources). Other 17 papers were included in the review as they were relevant to the discussion on PSS software for a maptable. These papers did not appear in the initial result of the search; however, authors were aware of them, or they were found in the bibliography of the reviewed papers. Appendix A contains a list of the selected papers.

\subsection{Semi-Structured Interviews with Intended Users as Part of Human-Centered Design and Agile User Stories}

In this paper, we employed a HCD to involve the intended users in the conception of the tool. Hence, we started the conception process of a digital interactive tool to support collaborative spatial planning by identifying intended user groups and their characteristics, selecting a sample from identified groups and interviewing them to generate user stories in a posterior phase. Four main groups of intended users were identified for semi-structured interviews, namely planning researchers, GIS experts, planning practitioners, and laypersons [27]. All of the identified user groups had to be aware of a maptable and had used it at least once. Planning researchers are defined as professionals primarily dedicated to planning studies, whether having or not a background in GIS applications. Their research interest is mainly led by theoretical frameworks and planning problems instead of the supporting technology for addressing them. GIS experts are professionals or researchers highly skilled in the application of GIS technologies; they may have some knowledge of planning, but their central interest is the exploitation of GIS capabilities. This type of users can perform the role of chauffeur, develop models to be used in a maptable-based PSS workshop, or provide technical support during such a workshop. A planning practitioner is understood as a planning professional working in a private or public organization to develop plans or carry out projects related to land use interventions. This type of users may have or not expertise in GIS applications. A layperson or lay user refers to a person without specialized knowledge in planning or GIS. This kind of user can also be referred to as residents that have prior experience in planning sessions.

The objective of the interviews was to unpack user perspectives concerning the current validity and importance of the requirements found in the literature and identify new ones that may not have been reported on it. We interrogated the users' previous experience to understand the kind of application for which they have applied a maptable. Besides, we asked for the problem addressed, stakeholders involved in the process, the spatial analysis applied and the planning phase in which a maptable was used. We also enquired about the shortcomings of the PSS tool applied or aspects to be improved, and the expectations concerning a 'must-have' functionality of a new PSS tool under design. Furthermore, we asked for the need of support for different space-time settings and individual footprints, i.e., tracking individual contributions during a planning session with a maptable. The information collected through the interviews outlined above, was the input to extract user stories described in the following section.

In total, we interviewed 11 participants, 4 planning researchers, 3 GIS experts, 2 planning practitioners, and 2 laypersons. Those participants were selected given their experience with a maptable and their availability, e.g., time and location, for participating in the interviews. Interviews were (voice) recorded and summarized to provide the input for the systematic formulation of user stories. The interview process complied with the General Data Protection Regulation (GDPR) meaning participants were informed about the purpose of the interview, they gave consent to record it and to use it for the purpose of this research; collected data was not disclosed to third parties; and its processing and storage were performed following practices for data protection and privacy aligned with the GDPR.

Due to time availability and geographic location of our intended users, we derived Agile user stories from their interviews. Recordings and interview summaries were deeply scanned to extract expressions systematically. These impressions were translated into Agile user stories which are reported in the result section. Formulated user stories follow the template given in Box 1 by specifying 
a username or user role, the feature or functionality required and, optionally, the benefit that the user will attain by having that functionality in the tool. All user stories were checked by an external expert in software development and revised where applicable. In order to minimize the subjectivity endowed with this kind of data analysis method, interview audio, and summaries were revisited iteratively.

\subsection{Tool Conceptualization}

For the tool conceptualization we contrasted the requirements found during the literature review with those expressed as user stories. Besides, a baseline of functionalities provided in regular GI-based participatory tools such as annotated maps is taken as a basis of our tool. An annotated map enables users to explore spatial content encoded in geographic layers and add information via markers, comments, or media files. We also considered our own knowledge accumulated through the experiences obtained from attending or moderating planning workshops. The result of this conception process is presented through an illustration and a narrative describing the main components of our tool in Section 4.3.

\section{Results}

This section discloses the findings we obtained from the literature review and user interviews and presents the conceptualization of an interactive PSS tool for a maptable, narrowing down the many specific aspects to what is required in practice by users.

\subsection{A Maptable: Potential Shortcomings and Requirements of Maptable Software Applications}

Based on the literature, concerning: a) case studies where a maptable was applied; b) general shortcomings of the available PSS tools, i.e., software applications for this instrument; c) potential requirements; and d) our own experiences of maptable-based PSS workshops, we found the following.

Different studies in diverse sectors of applications emphasize the potential of a maptable to support collaborative spatial planning, for instance, to enhance the communication among different types of stakeholders, e.g., expert and non-expert, and offering analytical functionality to generate better-informed plans or proposals. The majority of the studies concerned strategic urban planning issues [42,43], followed by planning studies related to climate $[15,19,44,45]$ and environmental health [17]. We also found applications in the energy sector [18], and transportation [29]. In several of those studies, scholars reported that the enhanced interaction provided by a maptable might lead towards knowledge sharing, knowledge combination, or consensus-building [46,47].

Although a maptable has shown potential as demonstrated by the case studies, the authors also encountered some limitations. For example, it can accommodate only a limited number of people and can be intimidating for elderly or low digital literate stakeholders [18]. Case studies also reported shortcomings of software applications, i.e., the digital tool implemented in a maptable, when delivering spatial content. This aspect is the focus of our research. The issues that were identified concerning software applications for a maptable are summarized as follows:

- Single root: GIS desktop applications do not fully exploit the touch capabilities because they have single-user roots, i.e., they were designed for a single user, i.e., one user at the time [32,48].

- Expert systems: conventional tools are developed for and by experts that can handle sophisticated technologies which may limit the participation of non-expert stakeholders [4].

- Turn-taking: Turn-taking is a regular implementation of the collaborative group work, i.e., stakeholders use the software in turns, but the software itself is not aware of this and does not keep a record of those turns [49]. Hence, individual contributions cannot be traced.

- Software offer: the offer of mature and stable GI-based software specially designed for supporting large touch devices and collaborative group work is scarce. Besides, the current offer does not satisfy the needs of most users [8] 
- Open source software: open-source software tools that allow for collaborative development of extensible applications are scarce [7].

In addition to the general software shortcomings mentioned above, we also listed the desired capabilities of a planning support tool as envisioned by researchers. We categorized those capabilities, also known as potential requirements as follows:

1. navigation,

2. data input,

3. data management,

4. spatial analysis,

5. visualization and,

6. other capabilities mainly dealing with extensibility and performance of the PSS tool.

Concerning navigation, scholars documented the need for mobile-oriented designed applications. This means apps with intuitive GUI (Graphical User Interface) adapted to an interactive surface, i.e., simple and minimal menus using larger buttons, and gesture-based user interaction [50-52].

Capabilities for data input concerned advanced editing, namely: automatic closing of shapes, easy drawing of regular forms; copying, pasting, resizing, and rotate features; freehand drawing and annotation; adding markers or comments and typing via a virtual keyboard $[43,46,48,50,51,53]$.

Potential requirements related to data management address information reuse and integration; for example, the integration of information via databases, map libraries and multiple sketching layers. Besides, import and export of parameters values, results or maps is desired [45,50].

With regard to spatial analysis, scholars reported scenario planning, timely evaluation of alternatives via indicators, embedded GIS functionality and cost-benefit analysis as pivotal functions expected in a PSS tool $[12,15,18,19,43]$.

In terms of visualization, scholars remarked the importance of a balance in the data used to limit the cognitive effort of stakeholders, e.g., by limiting the number of concurrent layers being displayed, showing a reduced number of indicators at once, and providing different visualization forms understandable for a wider audience, e.g., dashboards, linked visualizations of maps, charts, and graphs and efficient rendering of large datasets $[12,19,29,43,50]$. In addition, intuitive and interactive styling and advanced visualization such as $3 \mathrm{D}$ views were listed as needed for supporting planning processes [18,43].

Other relevant qualities for a PSS as understood by researchers refer to a) the performance of the tool, e.g., handling large datasets or cloud computing; b) the learning curve, i.e., guidance through workflows, well-structured help; and c) adaptable and understandable models [12,43,51,54,55].

In summary, based on the potential requirements and shortcomings found in the literature and our previous experience in attending and moderating planning workshops, we identified four dimensions to structure our interviews, namely:

1. the principal spatial analysis of a maptable PSS tool,

2. the must-have functionalities of a maptable PSS tool,

3. tracking of individual contributions and,

4. space-time settings for group work collaboration.

Dimensions a and $\mathrm{b}$ were chosen to stress the core of requirements that would enable users to achieve their intended tasks when applying the tool being conceptualized, i.e., the principal spatial analysis that is required and the minimum essential set of functions for a map-based PSS tool. Dimensions $\mathrm{c}$ and $\mathrm{d}$ were selected on the basis of our experience gathered during attending and moderating previous maptable-based PSS workshops, e.g., the limited window in space and time that people have to participate in a workshop and the lack of support in discriminating individual contributions. Besides, these dimensions imply functionalities that are not regularly included in a PSS tool, because they go beyond the standard or base level of performance of a GI-based tool. 


\subsection{User Stories Derived from the Interviews}

In the following sections, we analyze the responses of the identified user groups structured by the identified requirements from Section 4.1, namely a) principal spatial analysis, b) must-have functionalities, c) tracking of individual contributions, and d) space-time settings for group work collaboration. For each dimension, exemplifying user stories are given, following the template presented in Box 1. For readability, we refer to our intended users in a general way, e.g., researchers instead of interviewed researchers. Also, when we refer to statements made by a specific respondent we identified her/him as follow: $P_{i}$ represents a planning practitioner ( $i$ ranges from 1 to 2 ), $R_{j}$ refers to a researcher ( $j$ ranges from 1 to 4$), G_{k}$ refers to a GIS expert ( $k$ ranges from 1 to 3 ), and $L_{m}$ states for a layperson, with $m$ ranging from 1 to 2 .

a) Principal Spatial Analysis

We found that the majority of case studies as reported by our respondents applied a maptable during an exploratory phase (intelligence), i.e., for gaining an understanding of the planning problem or issue at hand. In those cases, map visualization and essential input data functions, e.g., adding markers, were sufficient for the intended purpose. In other instances, impact evaluation via indicators was the principal spatial analysis used in planning workshops giving stakeholders immediate feedback on specific intervention proposals. Table 1 lists the responses of our interviewees, followed by examples of extracted user stories related to this topic.

Table 1. Principal spatial analysis.

\begin{tabular}{ccccc}
\hline $\begin{array}{c}\text { Group } \backslash \text { Type of } \\
\text { Analysis }\end{array}$ & $\begin{array}{c}\text { Visualization/ } \\
\text { Mapping }\end{array}$ & $\begin{array}{c}\text { Impact Evaluation } \\
\text { (Indicators) }\end{array}$ & SMCE & $\begin{array}{c}\text { Simple } \\
\text { Calculations }\end{array}$ \\
\hline Practitioners & 2 & - & - & - \\
Researchers & 4 & 1 & 1 & - \\
GIS experts & 2 & 1 & 1 & 1 \\
Lay persons & - & 2 & - & - \\
\hline
\end{tabular}

Example of user stories:

As a planning practitioner, I want to integrate different layers so that I can quickly identify ideal locations for certain facilities.

As a researcher, I want to have a scenario analysis combined with impact analysis of alternatives so that I can see the effect of specific measures on the problem being tackled.

b) Must-have functionalities

In this dimension, interviewed users responded at different levels of details providing statements that were classified as non-functional and functional requirements. The non-functional requirements, also known as quality attributes, describe how the tools should be whereas the functional requirements refer to specific capabilities, e.g., calculations, input type, etc., desired for the new tool under construction. We listed below a summary of the must-have capabilities according to our interviewees, the first set of qualities are rather generic, whereas the following are specific:

Non-functional requirements:

- Customizable: a tool adjustable to the context and topic under discussion.

- Transparent: the user can know and modify any assumption of the tool.

- Interoperable: meaning easy integration with common GIS applications and formats, and portability of the resulting analysis.

- More intuitive interface: the UI of the new tool looks and works similarly to a tablet or mobile phone, e.g., simple interfaces with bigger buttons.

- Web-based: the app is available online. 
- OS: the app is Open Source.

- Reliable: recovers from failures with minimum data loss.

- Complexity: the complexity of the tool according to the tackled phase of planning and the specific intended stakeholder participating in a workshop mediated by a maptable.

- Modularity: the application allows for a progressive addition of functions as the planning process advance.

Functional requirements:

- Data collection: adding markers to the map concerning the issue at stake.

- Sketching and adding notes: free-hand drawing and adding text notes on the map canvas.

- Impact assessment: provides immediate feedback on the effects on predefined indicators of sketched interventions being discussed.

- Scenario analysis: constructs and analyses future conditions concerning the problem at stake.

- (user-driven) Spatial Multi-criteria Evaluation (SMCE): stakeholders can perform a multi-criteria evaluation and tune its parameters.

- 3D views: visualization of tri-dimensional data.

Examples of user stories:

As a researcher, I want to have a GUI rich in pictures so that people with low education (e.g., unable to read) can easily use the application.

As a GIS expert, I want an application available on the web so that more people can participate remotely and integrate the result of that interaction into the discussion mediated by a maptable.

As a Researcher, I want an open-source application comparable to current private touch-oriented apps for a maptable so that users can have a satisfactory experience without the restrictions of private software.

As a layperson, I want to have an app that does not freeze so that participants remain engaged/active in the discussion.

As a Planning practitioner, I want to quickly draw in a few steps so that the process of proposing interventions can be faster.

As a Planning practitioner, I want to sketch on the maptable using free-hand gestures so that I can express ideas or concepts as I normally do during design discussions.

c) Tracking of Individual Contributions

Common applications for maptable-based PSS tools do not offer the capability for keeping track of individual contributions. We explored to what extent our intended users do need to discriminate individual inputs during a planning workshop where a maptable is used. Table 2 presents gathered responses in this matter, in which we observe that more than half of our participants judged tracking individual contributions of stakeholders as not important or slightly important.

Table 2. Tracking individual contributions.

\begin{tabular}{ccccc}
\hline Group $\backslash$ Item & $\begin{array}{c}\text { Very } \\
\text { Important }\end{array}$ & $\begin{array}{c}\text { Moderately } \\
\text { Important }\end{array}$ & $\begin{array}{c}\text { Slightly } \\
\text { Important }\end{array}$ & $\begin{array}{c}\text { Not } \\
\text { Important }\end{array}$ \\
\hline Practitioners & 1 & - & 1 & - \\
Researchers & 1 & - & 1 & 2 \\
GIS Experts & - & 1 & - & 2 \\
Lay Persons & - & 1 & - & 1 \\
\hline
\end{tabular}

\section{Example of user stories:}

As a researcher, I want to track individual inputs so that I can understand how stakeholders become more concrete across the planning session or whether changes in the proposal can be related to a communicational process (e.g., learning). 
As a planning practitioner, I want to be able to discriminate individual interventions of participants so that I can understand who proposed a particular intervention during the planning workshop.

d) Space-Time Settings for Group Work Collaboration

In general, in the geospatial community, there is an increasing interest in supporting multi-user collaboration in different space-time settings, particularly in asynchronous distributed environments [56]. In this dimension, we enquired our users' perspective concerning how useful it would be having extended capabilities to accommodate interactions among stakeholders in distributed-asynchronous and distributed-synchronous settings (see Figure 2). This feature goes beyond the current support offered by a maptable in a co-located-synchronous setting that is typical of face-to-face planning workshops. Responses collected are listed in Table 3.

Table 3. Need for supporting different space-time settings.

\begin{tabular}{|c|c|c|c|c|c|}
\hline Setting & Group $\backslash$ Item & $\begin{array}{c}\text { Very } \\
\text { Important }\end{array}$ & $\begin{array}{l}\text { Moderately } \\
\text { Important }\end{array}$ & $\begin{array}{c}\text { Slightly } \\
\text { Important }\end{array}$ & $\begin{array}{c}\text { Not } \\
\text { Important }\end{array}$ \\
\hline \multirow{4}{*}{ Distributed-Synchronous } & Practitioners & - & - & 2 & - \\
\hline & Researchers & - & - & 3 & 1 \\
\hline & GIS experts & - & - & - & 3 \\
\hline & Laypersons & - & - & 1 & 1 \\
\hline \multirow{4}{*}{ Distributed-Asynchronous } & Practitioners & - & - & - & 2 \\
\hline & Researchers & - & 1 & 2 & 1 \\
\hline & GIS experts & - & 2 & 1 & - \\
\hline & Laypersons & - & 1 & - & 1 \\
\hline
\end{tabular}

In general, respondents considered the support for the distributed-synchronous setting not important or slightly important. However, some respondents envisioned potential uses cases that may require this kind of configuration, for example, in a professional environment where users remotely need to co-design proposals, and it is not possible to timely meet in face-to-face. Additional insights emerged concerning this issue. We listed those below:

- As participants or stakeholders, being located in different places, work on the same problem perhaps in different geographic contexts, a competitive rather than collaborative behavior may be triggered $\left(L_{1}\right)$. Hence, there is a potential risk of a group dominating the discussion $\left(R_{2}, G_{1}\right)$. Besides, stakeholders need to feel comfortable with the applied technology, i.e., a maptable and the software application to effectively participate in a discussion $\left(\mathrm{L}_{1}\right)$.

- The group dynamic occurring in a particular space can be disturbed by the communication with another group. Hence, there is a risk of diverting the discussion from the planning problem at stake by focusing on the interaction with the other group $\left(G_{1}\right)$.

- The logistic effort required to configure such a system to support distributed-synchronous setting would be quite complex and perhaps might not add significant value to the planning process. Besides, the benefits of applying a maptable rely on the face-to-face interaction among stakeholders that would be impeded by the increased complexity to synchronize inputs from remote and local groups $\left(\mathrm{R}_{1}\right)$.

- Communication among different groups working on a maptable, e.g., two parallel workshops could be useful for sharing results that each group achieved separately, discussing them and perhaps building a consensual outcome $\left(\mathrm{G}_{3}\right)$.

Respondents reacted-to some extent-positively on the question of supporting distributed asynchronous settings in combination with a maptable-based workshop. Thus, although practitioners did not find this quality as relevant, more than a third of our interviewees recognized this aspect as moderately important. Use cases for this setting concerned data collection processes, e.g., collecting 
user preferences or knowledge relating to a specific planning issue via annotated maps, online survey, etc. Respondents provided their perspective on this issue as summarized below:

- Often, the workshop participants, i.e., stakeholders, want to know people preferences on the problem under discussion. However, those processes should not be synchronized $\left(\mathrm{R}_{1}, \mathrm{G}_{3}\right)$. Instead, it is useful to have those preferences elicited prior to the workshop, e.g., via online surveys, geo-questionnaires or similar techniques and incorporate them as an input for the discussion $\left(\mathrm{R}_{2}, \mathrm{G}_{1}\right)$.

- A potential use case of a distributed and asynchronous setting including a maptable is a variation of the think-pair-share approach $\left(G_{2}\right)$ where users have their device, e.g., mobile phone or tablet for data collection or design proposals and their inputs are shared in a next group session. Then, the discussion on a maptable can take the input collected from individual participants or pairs into account $\left(\mathrm{P}_{1}, \mathrm{G}_{2}\right)$.

- People contributing to a data collection process that served as input for a maptable session should be able to know about the overall result of the data collection process, e.g., aggregated responses, and the outcome that stakeholder achieved using that elicited data $\left(\mathrm{G}_{1}\right)$.

Example of user stories:

As a GIS expert, I want to have seamless integration between mobile data collection and the application in a maptable so that I can use the data collected in the field during a planning workshop without much effort.

As a researcher, I want to collect people's preferences beforehand so that those preferences can be used during a workshop session.

\subsection{An Interactive Tool for a Maptable: A Conceptualization from User Stories}

In the previous section, we elaborated collected responses with respect to the selected dimensions namely a) the principal spatial analysis, b) the must-have functionalities, c) tracking of individual contributions, and d) space-time settings for group work collaboration. Besides, we provided examples of user stories extracted from those responses. Here, building on the results for the selected dimensions and taking into account that there exists a difference between what can be technically supported and what users need [7,57], we present the main building blocks of the digital maptable tool (i.e., a software application) to support a PSS workshop in a planning process, illustrated in Figure 4. The envisioned tool has three central components offering support concerning mapping, analysis, and space-time settings (see Figure 2). The mapping support component contains three subcomponents, namely interactive map, data input and layer management. The interactive map provides a visual workspace where stakeholders can explore geographic information, i.e., geographic layers, through gesture navigation tools such as pinch, pan, rotate, etc. The data input element enables stakeholders to input data, i.e., attributes or characteristics related to a particular location represented in one or more layers that are handled by the layer management. Layers are usually offered by loading local files or consuming geoservices. Through the mapping support component, participants can explore geographic information such as plan interventions, create sketches, or submit data linked to a location via marker or pin. The interaction provided by the mapping support component is compared to an annotated map as it accommodates preferences collection, data input or local knowledge elicitation.

The analysis component (analytical support) concerns evidence-based methods to tackle the problem at hand. We distinguish two sets of analytical functions. The first set refers to standard features expected for most of our intended users. Compiled user stories indicate that users mainly need SMCE, scenario development, impact assessment via indicators and sketching. These analytical functions, including their output visualization, e.g., an indicator chart, can be applied to produce better-informed plans or decisions [44]. The second set of analytical functions includes advanced functionality that is specific to the problem at stake and the purpose for which a maptable will be applied. In this way, the application contains a set of common functions that most users require but allows for extension through the 
advanced and problem-based functions to be developed in close collaboration with stakeholders of the application, i.e., following an HCD approach. The space-time support component provides functions to accommodate participation in two different space-time settings: co-located synchronous and distributed asynchronous since compiled user stories confirmed some application cases for these settings (see the previous section). For co-located and synchronous settings, the conceptualized tool enables participation via gesture support, i.e., pinch, pan, minimal use of regular mouse and keyboard and a mobile-oriented GUI design, e.g., bigger buttons and simple interface. For distributed and asynchronous settings, the tool provides easy integration with GI-based open source tools for mobile data collection. The three building blocks of the tool aim to support the social interaction (synchronous and asynchronous) among stakeholders and the analysis required to support collaborative spatial planning.

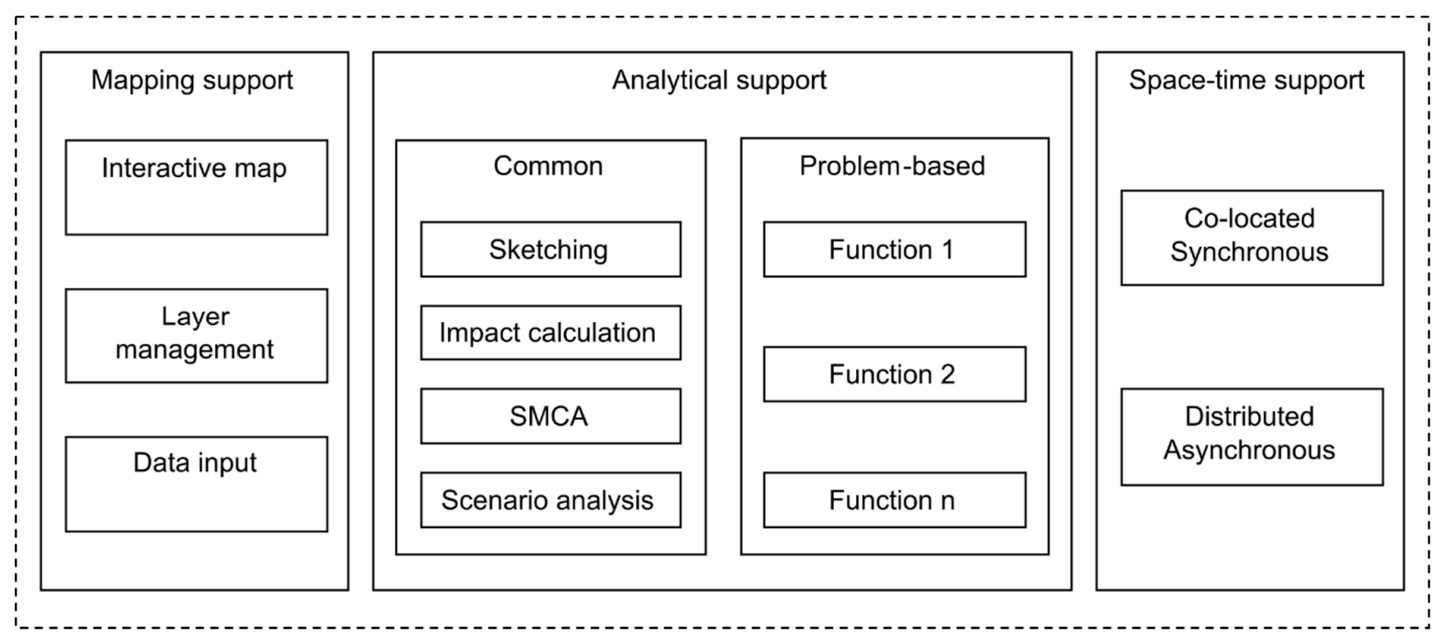

Figure 4. Central components of an interactive PSS tool for a maptable.

\section{Discussion and Conclusions}

The central aim of this paper is to conceptualize an interactive PSS tool to be used in a maptable that carefully considers requirements expressed by intended users of such a tool.

By involving the intended users in the conception of the tool, we revealed a discrepancy between the understanding of scholars and developers with respect to what users need and what they do. Thus, concerning the principal spatial analysis dimension, most cases reported by our respondents did not perform spatial analysis because the process was at an early stage, or the intended outcome was knowledge elicitation or social learning. In other cases, the central spatial analysis applied was the calculations of predefined indicators to assess the impact of proposed interventions. This indicates that often scholars/developers seem to be more ambitious than our respondents when addressing spatial planning processes. Hence, what our intended user group is requiring is tailored but straightforward instruments, rather than complicated or time-consuming models. This issue was also discussed in earlier studies [6].

As regards must-have functionalities of the PSS tool to be developed, our respondents provided insights at different levels of abstraction, showing a preference towards contextualized tools. In other words, a tool adjustable to the planning problem being addressed and the characteristics of the stakeholders to enable equity in participation. With respect to this, some of the extracted requirement were comparable with those found in the literature, whereas others were not mentioned, e.g., cloud computing or movement data analysis $[43,56]$. This led us to argue that, in general, in the context of collaborative spatial planning processes mediated by a maptable, users want simple, transparent, fast-to-setup, interoperable, and affordable tools that aid in their planning tasks.

Concerning the support of group work collaboration via recording individual contribution, our users found this feature irrelevant, especially when the problem at stake addresses personal opinions rather than institutional perspectives. This result challenges findings of previous studies [49], but 
needs to be further researched as we conducted interviews with only a small number of potential users. In terms of extended capabilities of a maptable for supporting distributed settings, e.g., as part of a collaborative GIS [58], users reacted moderately positive towards distributed-asynchronous setting and the use of the output of such a process as input for planning workshops mediated by a maptable. In contrast, our respondents were sceptic concerning distributed-synchronous settings, arguing that such setup imposes complexity and demands technical facilities, e.g., a broadband and stable internet connection that is not always available. This finding is quite interesting because the need for supporting group work in different space-time settings has been broadly discussed [28,59] but, so far, few software solutions implemented capabilities for those settings [34]. Also, in the field of spatial planning, detailed studies on this issue require further investigation as our number of interviewees is modest.

For several years, scholars discussed the mismatch between what planning practice needs and what has been developed. In this research, we involved representative intended users of our PSS tool to be developed in the conceptualization process through a combination of methods, namely interviews and Agile user stories. By extracting user stories from the interviews, we have conceptualized a tool that effectively addresses the requirements of those intended users. However, elicited requirements were rather generic, and new ones might arise or evolve in the implementation phase which can be handled in iterative collaboration with users in an HCD approach. Our research has laid down the foundation for future maptable tool development to support collaborative planning processes. A next step in our research is to actually implement our conceptualized tool in a co-creation process fed by inputs collected in frequent iterations with a problem-specific focus group. Feedback will not only concern functionality, but also usability aspects of the tool.

Author Contributions: Conceptualization, Rosa Aguilar, Johannes Flacke, and Karin Pfeffer; Methodology, Rosa Aguilar; Formal Analysis, Rosa Aguilar; Investigation, Rosa Aguilar; Data Curation, Rosa Aguilar; WritingOriginal Draft Preparation, Rosa Aguilar; Writing-Review and Editing, Johannes Flacke and Karin Pfeffer; Visualization, Rosa Aguilar; Supervision, Johannes Flacke and Karin Pfeffer. All authors have read and agreed to the published version of the manuscript.

Funding: This research received no external funding.

Acknowledgments: We wish to express our gratitude to all the interviewees that enthusiastically responded to our questions. We express our gratitude also towards Matthias Kuhn, Luis Calisto, and Raghavendra Sharma for their support concerning software development practices. Also, our gratitude is deserved by Corné van Elzakker for his valuable suggestions concerning human-centered design guidelines.

Conflicts of Interest: The authors declare no conflict of interest.

\section{Appendix A Title and Reference of Selected Papers Used in the Identification of Shortcomings and Potential Requirements}

- Interactive Marine Spatial Planning: Siting Tidal Energy Arrays around the Mull of Kintyre [16].

- Map-Based Multicriteria Analysis to Support Interactive Land Use Allocation [60].

- Effectiveness of Collaborative Map-Based Decision Support Tools: Results of an Experiment [42].

- From Planning Support Systems to Mediated Planning Support: A Structured Dialogue to Overcome the Implementation Gap [4].

- Tables, Tablets and Flexibility: Evaluating Planning Support System Performance under Different Conditions of Use [55].

- $\quad$ Exploring Landscape Engagement through a Participatory Touch Table Approach [61].

- Beauty and Brains: Integrating Easy Spatial Design and Advanced Urban Sustainability Models [43].

- Collaborative Interaction with Geospatial Data—a Comparison of Paper Maps, Desktop GIS and Interactive Tabletops [62].

- Collaborative Use of Geodesign Tools to Support Decision-Making on Adaptation to Climate Change [12].

- What Do Users Really Need? Participatory Development of Decision Support Tools for Environmental Management Based on Outcomes [7]. 
- $\quad$ The V-City Project [63].

- Using Geodesign to Develop a Spatial Adaptation Strategy for Friesland [19].

- A Collaborative Multi-Touch, Multi-Display, Urban Futures Tool [44].

- SimLandScape, a Sketching Tool for Collaborative Spatial Planning [64].

- Developing a Conceptual Framework for Visually-Enabled Geocollaboration [32]

- Using Maptable®to Learn about Sustainable Urban Development [54].

- The Added Value of Planning Support Systems: A Practitioner's Perspective [3].

- Towards Satisfying Practitioners in Using Planning Support Systems [8].

- Interactive Knowledge Co-Production and Integration for Healthy Urban Development [17].

- SUSS Revisited: An Interactive Spatial Understanding Support System (ISUSS) for Collaborative Spatial Problem Structuring [65].

- Interactive Cumulative Burden Assessment: Engaging Stakeholders in an Adaptive, Participatory and Transdisciplinary Approach [46].

- Simlandscape: Serious Gaming in Participatory Spatial Planning [66].

- Enabling Interaction with Single User Applications through Speech and Gestures on a Multi-User Tabletop [49].

- Adaptation Planning Support Toolbox: Measurable Performance Information Based Tools for Co-Creation of Resilient, Ecosystem-Based Urban Plans with Urban Designers, Decision-Makers and Stakeholders [45].

- $\quad$ Augmenting Quantum-GIS for Collaborative and Interactive Tabletops [51].

- Perception and Reality: Exploring Urban Planners' Vision on GIS Tasks for Multi-Touch Displays [48].

- Socio-Technical PSS Development to Improve Functionality and Usability-Sketch Planning Using a Maptable [50].

- Planning Support System for Climate Adaptation: Composing Effective Sets of Blue-Green Measures to Reduce Urban Vulnerability to Extreme Weather Events [15].

- An Emerging Trend of GIS Interaction Development: Multi-Touch GIS [52].

\section{References}

1. Foth, M.; Bajracharya, B.; Brown, R.; Hearn, G. The Second Life of urban planning? Using NeoGeography tools for community engagement. J. Locat. Based Serv. 2009, 3, 97-117. [CrossRef]

2. Lin, Y.; Geertman, S. Smart governance, collaborative planning and planning support systems: A fruitful triangle? In Lecture Notes in Geoinformation and Cartography; Springer: Cham, Switzerland, 2015; Volume 213, pp. 261-277.

3. Pelzer, P.; Geertman, S.; van der Heijden, R.; Rouwette, E. The added value of Planning Support Systems: A practitioner's perspective. Comput. Environ. Urban Syst. 2014, 48, 16-27. [CrossRef]

4. Te Brömmelstroet, M.; Schrijnen, P.M. From planning support systems to mediated planning support: A structured dialogue to overcome the implementation gap. Environ. Plan. B Plan. Des. 2010, 37, 3-20. [CrossRef]

5. Falco, E.; Kleinhans, R. Digital Participatory Platforms for Co-Production in Urban Development. Int. J. E-Plan. Res. 2018, 7, 1-27. [CrossRef]

6. Geertman, S. PSS: Beyond the implementation gap. Transp. Res. A 2017, 104, 70-76. [CrossRef]

7. Hewitt, R.; Macleod, C. What Do Users Really Need? Participatory Development of Decision Support Tools for Environmental Management Based on Outcomes. Environments 2017, 4, 88. [CrossRef]

8. Russo, P.; Lanzilotti, R.; Costabile, M.F.; Pettit, C.J. Towards satisfying practitioners in using Planning Support Systems. Comput. Environ. Urban Syst. 2018, 67, 9-20. [CrossRef]

9. Pettit, C.; Bakelmun, A.; Lieske, S.N.; Glackin, S.; Hargroves, K.C.; Thomson, G.; Shearer, H.; Dia, H.; Newman, P. Planning support systems for smart cities. City Cult. Soc. 2018, 12, 13-24. [CrossRef]

10. Vonk, G.; Geertman, S.; Schot, P. Bottlenecks blocking widespread usage of planning support systems. Environ. Plan. A 2005, 37, 909-924. [CrossRef] 
11. Lenferink, S.; Arciniegas, G.; Samsura, A.; Carton, L. Integrating geodesign and game experiments for negotiating urban development. Res. Urban Ser. 2016, 4, 71-92.

12. Eikelboom, T.; Janssen, R. Collaborative use of geodesign tools to support decision-making on adaptation to climate change. Mitig. Adapt. Strateg. Glob. Chang. 2017, 22, 247-266. [CrossRef] [PubMed]

13. Warren-Kretzschmar, B.; Von Haaren, C. Communicating spatial planning decisions at the landscape and farm level with landscape visualization. iFor. Biogeosci. For. 2014, 7, 434-442. [CrossRef]

14. Rogers, Y.; Lindley, S. Collaborating around vertical and horizontal displays: Which way is best. Interact. Comput. 2004, 16, 1133-1152. [CrossRef]

15. Voskamp, I.M.; Van de Ven, F.H.M. Planning support system for climate adaptation: Composing effective sets of blue-green measures to reduce urban vulnerability to extreme weather events. Build. Environ. 2014, 83, 159-167. [CrossRef]

16. Alexander, K.A.; Janssen, R.; Arciniegas, G.; O’higgins, T.G.; Eikelboom, T.; Wilding, T.A.; Krkosek, M. Interactive Marine Spatial Planning: Siting Tidal Energy Arrays around the Mull of Kintyre. PLoS ONE 2012, 7, e30031. [CrossRef]

17. Shrestha, R.; Köckler, H.; Flacke, J.; Martinez, J.; van Maarseveen, M. Interactive Knowledge Co-Production and Integration for Healthy Urban Development. Sustainability 2017, 9, 1945. [CrossRef]

18. Flacke, J.; de Boer, C. An Interactive Planning Support Tool for Addressing Social Acceptance of Renewable Energy Projects in The Netherlands. ISPRS Int. J. Geo-Inf. 2017, 6, 313. [CrossRef]

19. Janssen, R.; Eikelboom, T.; Verhoeven, J.; Brouns, K. Using Geodesign to Develop a Spatial Adaptation Strategy for Friesland. In Geodesign by Integrating Design and Geospatial Sciences; Springer: Cham, Switzerland, 2014; pp. 103-116. ISBN 978-3-319-08298-1.

20. Pelzer, P.; Arciniegas, G.; Geertman, S.; Lenferink, S. Planning Support Systems and Task-Technology Fit: A Comparative Case Study. Appl. Spat. Anal. 2015, 8, 155-175. [CrossRef]

21. Flacke, J.; Shrestha, R.; Aguilar, R. Strengthening Participation using Interactive Planning Support Systems: A Systematic Review. ISPRS Int. J. Geo-Inf. 2019. under review.

22. Pelzer, P.; Goodspeed, R.; te Brömmelstroet, M. Facilitating PSS workshops: A conceptual framework and findings from interviews with facilitators. In Lecture Notes in Geoinformation and Cartography; Springer: Cham, Switzerland, 2015; Volume 213, pp. 355-369.

23. Arciniegas, G.; Janssen, R. Spatial decision support for collaborative land use planning workshops. Landsc. Urban Plan. 2012, 107, 332-342. [CrossRef]

24. Nuissl, H.; Heinrichs, D. Fresh wind or hot air-does the governance discourse have something to offer to spatial planning? J. Plan. Educ. Res. 2011, 31, 47-59. [CrossRef]

25. Jones, H. Taking Responsibility for Complexity How Implementation Can Achieve Results in the Face of Complex Problems; Oversees Development Institute (ODI): London, UK, 2011; ISBN 9781907288395.

26. Georgiadou, Y.; Reckien, D. Geo-Information Tools, Governance, and Wicked Policy Problems. ISPRS Int. J. Geo-Inf. 2018, 7, 21. [CrossRef]

27. Anokye, N.A. Stakeholder Participation in Water Resources Management: The Case of Densu Basin in Ghana. Ph.D. Thesis, Vrije Universiteit Amsterdam, Amsterdam, The Netherlands, 2013.

28. Isenberg, P.; Elmqvist, N.; Scholtz, J.; Cernea, D.; Kwan-Liu, M.; Hagen, H.; Kwan-Liu, M.; Hagen, H. Collaborative visualization: Definition, challenges, and research agenda. Inf. Vis. 2011, 10, 310-326. [CrossRef]

29. Nagel, T.; Maitan, M.; Duval, E.; Vande Moere, A.; Klerkx, J.; Kloeckl, K.; Ratti, C. Touching transport-A case study on visualizing metropolitan public transit on interactive tabletops. In Proceedings of the 2014 International Working Conference on Advanced Visual Interfaces the-AVI '14, Como, Italy, 27-30 May 2014; pp. 281-288.

30. Simon, H.A. The New Science of Management Decision: The Ford Distinguished Lectures; Harper \& Brothers: New York, NY, USA, 1960.

31. Pelzer, P.; Geertman, S.; Van Der Heijden, R. Knowledge in communicative planning practice: A different perspective for planning support systems. Environ. Plan. B Plan. Des. 2015, 42, 638-651. [CrossRef]

32. Maceachren, A.M.; Brewer, I. Developing a conceptual framework for visually-enabled geocollaboration. Int. J. Geogr. Inf. Sci. 2004, 18, 1-34. [CrossRef]

33. Kahila, M.; Kyttä, M. SoftGIS as a Bridge-Builder in Collaborative Urban Planning. In Planning Support Systems Best Practice and New Methods Geertman; John Stillwell, S., Ed.; Springer: New York, NY, USA, 2009; pp. 389-411. ISBN 978-1-4020-8951-0. 
34. García-Chapeton, G.A.; Ostermann, F.O.; de By, R.A.; Kraak, M.J. Enabling collaborative GeoVisual analytics: Systems, techniques, and research challenges. Trans. GIS 2018, 22, 640-663. [CrossRef]

35. Flacke, J.; Boer, C.; de van den Bosch, F.; Pfeffer, K. Interactive Planning Support Systems with Citizens: Lessons Learned from Renewable Energy. In Handbook of Planning Support Science; Geertman, S., Stillwell, J., Eds.; Edward Elgar Publishing: Cheltenham, UK, 2020; pp. 482-504.

36. Manifesto for Agile Software Development. Available online: http://agilemanifesto.org/ (accessed on 18 April 2018).

37. Brhel, M.; Meth, H.; Maedche, A.; Werder, K. Exploring principles of user-centered agile software development: A literature review. Inf. Softw. Technol. 2015, 61, 163-181. [CrossRef]

38. Agile Alliance What Is Role-Feature-Reason? Available online: https://www.agilealliance.org/glossary/rolefeature/ (accessed on 27 February 2019).

39. Dimitrijević, S.; Jovanovic, J.; Devedžić, V. A comparative study of software tools for user story management. Inf. Softw. Technol. 2015, 57, 352-368. [CrossRef]

40. Wallin, S.; Horelli, L.; Saad-Sulonen, J. Digital Tools in Participatory Planning; Wallin, S., Horelli, L., Saad-Sulonen, J., Eds.; Centre for Urban and Regional Studies Publications: Helsinki, Finland, 2010; ISBN 9789526032597.

41. Ramasubramanian, L.; Albrecht, J. Essential Methods for Planning Practitioners: Skills and Techniques for Data Analysis, Vizualization, and Communication; Springer: Cham, Switzerland, 2018.

42. Arciniegas, G.; Janssen, R.; Rietveld, P. Effectiveness of collaborative map-based decision support tools: Results of an experiment. Environ. Model. Softw. 2013, 39, 159-175. [CrossRef]

43. Dias, E.; Linde, M.; Rafiee, A.; Koomen, E.; Scholten, H. Beauty and Brains: Integrating Easy Spatial Design and Advanced Urban Sustainability Models. In Planning Support Systems for Sustainable Urban Development; Geertman, S., Toppen, F., Stillwell, J., Eds.; Springer: Berlin/Heidelberg, Germany, 2013; pp. 469-484. ISBN 978-3-642-37533-0.

44. Van der Laan, M.; Kellet, R.; Girling, C. A collaborative multi-touch, multi-display, urban futures tool. In Proceedings of the Symposium on Simulation for Architecture \& Urban Design, San Diego, CA, USA, 7-10 April 2013; pp. 1-4.

45. Van de Ven, F.H.M.; Snep, R.P.H.; Koole, S.; Brolsma, R.; van der Brugge, R.; Spijker, J.; Vergroesen, T. Adaptation Planning Support Toolbox: Measurable performance information based tools for co-creation of resilient, ecosystem-based urban plans with urban designers, decision-makers and stakeholders. Environ. Sci. Policy 2016, 66, 427-436. [CrossRef]

46. Shrestha, R.; Flacke, J.; Martinez, J.; van Maarseveen, M. Interactive Cumulative Burden Assessment: Engaging Stakeholders in an Adaptive, Participatory and Transdisciplinary Approach. Int. J. Environ. Res. Public Health 2018, 15, 260. [CrossRef]

47. Pelzer, P.; Arciniegas, G.; Geertman, S.; De Kroes, J. Introduction to “Planning Support Systems for Sustainable Urban Development". In Planning Support Systems for Sustainable Urban Development; Geertman, S., Stillwell, J., Toppen, F., Eds.; Springer: Berlin/Heidelberg, Germany, 2013; Volume 195, pp. 1-15. ISBN 978-3-642-37532-3.

48. Vishkaie, R.S.; Levy, R. Perception and reality: Exploring urban planners' vision on GIS tasks for multi-touch displays. In Proceedings of the ACM Conference on Interactive Tabletops and Surfaces, Cambridge, MA, USA, 11-14 November 2012; pp. 265-270.

49. Tse, E.; Shen, C.; Greenberg, S.; Forlines, C. Enabling interaction with single user applications through speech and gestures on a multi-user tabletop. In Proceedings of the Working Conference on Advanced Visual Interfaces, Venice, Italy, 23-26 May 2006; pp. 336-343.

50. Vonk, G.; Ligtenberg, A. Socio-technical PSS development to improve functionality and usability-Sketch planning using a Maptable. Landsc. Urban Plan. 2010, 94, 166-174. [CrossRef]

51. Viard, A.; Bailly, G.; Lecolinet, E.; Fritsch, E. Augmenting Quantum-GIS for collaborative and interactive Tabletops. In Advances in Cartography and GIScience, Proceedings of the ICACI: International Cartographic Conference 2011, Paris, France, 3-8 July 2011; Springer: Berlin/Heidelberg, Germany, 2011; Volume 1, pp. $293-307$.

52. Zenghong, W.; Yufen, C.; Jiaquan, L. An Emerging Trend of GIS Interaction Development: Multi-Touch GIS. In Proceedings of the IET International Conference on Information Science and Control Engineering 2012 (ICISCE 2012), Shenzhen, China, 7-9 December 2012; Institution of Engineering and Technology: Stevenage, UK, 2012; pp. 1-4.

53. Isenberg, P.; Fisher, D.; Sharoda, A.P.; Morris Ringel, M.; Inkpen, K.; Czerwinski, M. Co-Located Collaborative Visual Analytics around a Tabletop Display. IEEE Trans. Vis. Comput. Graph. 2012, 18, 689-702. [CrossRef] 
54. Pelzer, P.; Arciniegas, G.; Geertman, S.; de Kroes, J. Using maptable®to learn about sustainable urban development. In Lecture Notes in Geoinformation and Cartography; Geertman, S., Toppen, F., Stillwell, J., Eds.; Springer: Berlin, Germany, 2013; pp. 167-186.

55. Champlin, C.; Te Brömmelstroet, M.; Pelzer, P. Tables, Tablets and Flexibility: Evaluating Planning Support System Performance under Different Conditions of Use. Appl. Spat. Anal. Policy 2019, 12, 467-491. [CrossRef]

56. Palomino, J.; Muellerklein, O.C.; Kelly, M. A review of the emergent ecosystem of collaborative geospatial tools for addressing environmental challenges. Comput. Environ. Urban Syst. 2017, 65, 79-92. [CrossRef]

57. Geertman, S. Participatory planning and GIS: A PSS to bridge the gap. Environ. Plan. B Plan. Des. 2002, 29, 21-35. [CrossRef]

58. Sun, Y.; Li, S. Real-time collaborative GIS: A technological review. ISPRS J. Photogramm. Remote Sens. 2016, 115, 143-152. [CrossRef]

59. Andrienko, G.L.; Andrienko, N.V.; Jankowski, P.; Keim, D.; Kraak, M.J.; MacEachren, A.; Wrobel, S. Geovisual analytics for spatial decision support: Setting the research agenda. Int. J. Geogr. Inf. Sci. 2007, 21, 839-857. [CrossRef]

60. Arciniegas, G.; Janssen, R.; Omtzigt, N. Map-based multicriteria analysis to support interactive land use allocation. Int. J. Geogr. Inf. Sci. 2011, 25, 1931-1947. [CrossRef]

61. Conniff, A.; Colley, K.; Irvine, K. Exploring Landscape Engagement through a Participatory Touch Table Approach. Soc. Sci. 2017, 6, 118. [CrossRef]

62. Döweling, S.; Tahiri, T.; Riemann, J.; Mühlhäuser, M. Collaborative interaction with geospatial data-A comparison of paper maps, desktop GIS and interactive tabletops. In Collaboration Meets Interactive Spaces; Springer: Cham, Switzerland, 2016; pp. 319-348. ISBN 9783319458533.

63. Himmelstein, J.; Balet, O.; Ganovelli, F.; Gobetti, E.; Specht, M.; Mueller, P.; Engels, C.; van Gool, L.; de la Rivière, J.; Cavazzini, A. The V-City Project. In Proceedings of the VAST: International Symposium on Virtual Reality, Archaeology and Intelligent Cultural Heritage, Prato, Italy, 18-21 October 2011; pp. 2-5.

64. Ligtenberg, A.; De Vries, B.; Vreenegoor, R.; Bulens, J. SimLandScape, a sketching tool for collaborative spatial planning. Urban Des. Int. 2011, 16, 7-18. [CrossRef]

65. Shrestha, R.; Flacke, J.; Martinez, J.; Maarseveen, M. van SUSS Revisited: An Interactive Spatial Understanding Support System (ISUSS) for Collaborative Spatial Problem Structuring. In Proceedings of the AESOP Conference From Control to Co-Evolution, Utrecht, The Netherlands, 9-12 July 2014.

66. Slager, K.; Ligtenberg, A.; de Vries, B.; de Waard, R.S. Simlandscape: Serious Gaming in Participatory Spatial Planning. In Proceedings of the 10th AGILE International Conference on Geographic Information Science, Aalborg, Denmark, 8-11 May 2007; pp. 1-11. 